\title{
Surgical Management of Secondary Cleft Palate in a Cat
}

\author{
V. Mahesh, G. Kamalakar*, C. Ansar Kamran and B.N. Nagaraja \\ Department of Veterinary Surgery and Radiology, Veterinary College, Hebbal, KVAFSU, \\ Bangalore - 560024, Karnataka, India \\ *Corresponding author
}

A B S T R A C T

\section{Ke ywords \\ Cat, Secondary cleft palate, Uranoplasty, Overlapping flap technique \\ Article Info \\ Accepted: \\ 15 July 2019 \\ Available Online: \\ 10 August 2019}

A young tom kitten was presented to the clinic with signs of mild respiratory distress, rhinitis, and part of ingesta coming out through nostrils. Careful examination revealed a narrow cleft in hard palate. Uranoplasty was done by overlapping flap technique under general anaesthesia. With good postoperative care and management, the animal recovered uneventfully.

\section{Introduction}

Congenital defects in cats are not uncommon. Various defects related to mouth in cats included cleft palate, prognathism, brachygnathism etc. (Pearson, 2006). Cleft palate is important one of these and may or may not involve the soft palate. Primary cleft palate is a cleft involving lips and premaxilla. Secondary cleft involves hard palate and or soft palate (Fossum, 2007). Incidence of palatal clefts was found to be more in female purebred cats of Siamese breed (Mulvihill et al., 1980). Genetics may be the main aetiology of this condition. Nutritional, hormonal, and mechanical factors can also enhance the formation of cleft palate in genetically predisposed foetuses. Intrauterine viruses and toxins that affect the mother during pregnancy may also increase the risk of cleft palate (Glennon, 2014). Presence of clefts interfere with suckling, causing leakage of ingesta through nostrils, rhinitis, sneezing, aspiration pneumonia, weight loss, etc. (Garcia, 2006). Surgery is the best option for treating these cases at an early date. In this report, we present a successful surgical treatment of a case of secondary cleft palate in a cat.

\section{Case history and Observations}

A 5 month old tom kitten was presented to the Dept. of Veterinary Surgery and Radiology, Veterinary College, Hebbal, Bengaluru with 
signs of mild respiratory distress, rhinitis, slow growth, and part of ingesta coming out through nostrils. Clinically the cat was normal with all the physiological parameters within normal range. Careful oral examination revealed a $1.5 \mathrm{~cm}$ long cleft in hard palate and not involved any part of soft palate. Moist rales heard on auscultation but radiography revealed no signs of pneumonia. It was decided to correct the defect by overlapping flap method.

\section{Results and Discussion}

The cat was premedicated with inj. Ceftriaxone plus Tazobactum @ $20 \mathrm{mg} / \mathrm{kg}$, Meloxicam@0.2 mg/ kg BW subcutaeously. Preanaesthetized the cat with Diazepam @ 0.5 $\mathrm{mg} / \mathrm{kg}$, induced and maintained with
Isoflurane inhalation anesthesia. A mucoperiosteal flap little longer and adjacent to the defect selected. Two perpendicular incisions, one at rostral and one at caudal end of the cleft was extending towards the left side half of the cleft palate and both were joined (Fig. 1). The flap was dissected, carefully elevated and rotated on to the defect. The mucosa of the cleft margin on opposite side was freshened. The flap was kept in position by simple interrupted sutures using Polyglactin 910 no. 4/0 (Fig. 2). Postoperatively it was on fluid therapy for 5 days and orally started with liquids and later semisolids to solid food. Antibiotic and antiinflammatory treatment was followed for next one week. Sutures were removed on $14^{\text {th }}$ postoperative day (Fig. 3). No complications observed and defect healed uneventfully.

Fig.1 Photograph showing cleft palate and incision lines for closing cleft palate

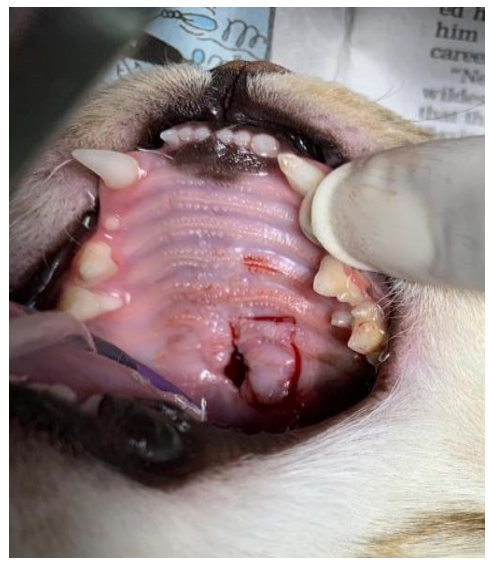

Fig.2 Photograph showing closed palatal cleft using simple interrupted sutures

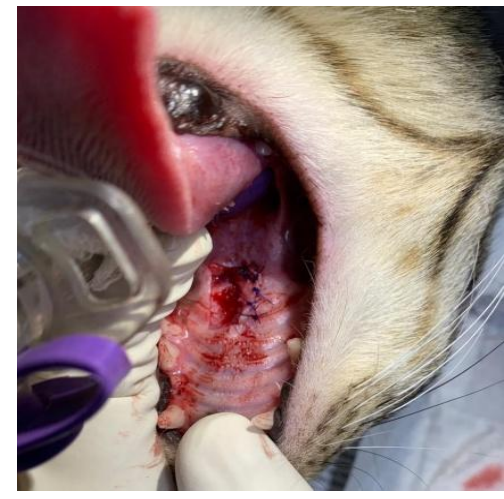


Fig.3 Photograph showing healed wound on $7^{\text {th }}$ post-operative day

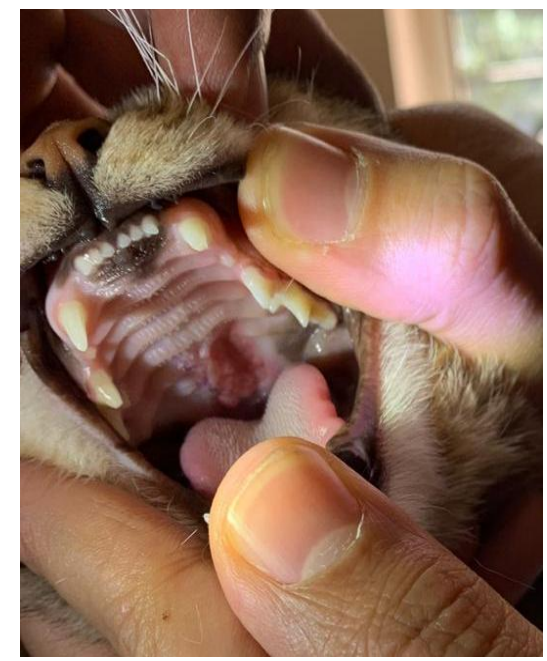

Oronasal fistula or cleft palate in this case is congenital one; however acquired ones because of trauma (Wilson, 2006) were also reported. The signs of rhinitis or aspiration pneumonia were gradually become more apparent owing to the gradual widening of hard palate defect. The signs observed viz, flow of ingesta / milk through nostrils, slow weight gain, pneumonia and occasional sneezing were due to passage of milk through the cleft into nasal cavity anteriorly into nostrils and posteriorly into lungs. Similar signs were also reported by Lee et al., (2006) and Wilson (2006). As the size of the cleft was very smaller, we preferred overlapping flap technique as indicated by Fossum (2007) in which the sutures won't be placed over the suture line. On the other hand, Tobias (2010) and Conze et al., (2018) used a sliding bipedicle flap (von Langenbeck) technique to close the defect. When the defect was too larger or wider to close, various authors used prosthetics like thermoplastic silicone (Conze et al., 2018), conical silastic prosthetic device (de Souza et al., 2005) and dental implant resin (Lee et al., 2006) to close the cleft. The anaesthetic regime (diazepam + Ketamine and Isoflurane) followed in this case, produced satisfactory surgical plane of anaesthesia. Overlapping technique was successful in our case however, few complications like wound dehiscence, infection were also reported (Wilson, 2006). Although there are various reasons for the development of congenital palatoschisis, there is a genetic predisposition (Moura et al., 2012) and castration of the animal is strongly advised.

\section{References}

Conze, T., Ritz, I., Hospes, R. and Wehrend, A. 2018. Management of Cleft Palate in Puppies Using a Temporary Prosthesis: A Report of Three Cases. Veterinary Science. 5: 61.

De Souza, H.J.M., Amorim, F.V., Corgozinho, K.B. and Tavares, R.R. 2005. Management of the traumatic oronasal fistula in the cat with a conical silastic prosthetic device. Journal of Feline Medicine and Surgery. 7: 129 133.

Fossum, T.W. 2007. Surgery of the oral cavity and oropharynx. In Small Animal Surgery, $2^{\text {nd }}$ ed. Mosby: St. Louis, MO, USA, pp. 274-306.

Garcia, J.F.R. Surgery of the soft and hard palate. 2006. Proceedings of the North American Veterinary conference volume 20 January 7-11, Orlando, 
Florida. Pp: $1438-1440$.

Glennon, J.C. 2014. Managing cleft palates. Veterinary specialities referral centre, December issue.

Lee, J.I, Kim, Y.S., Kim, M.J., Lee, J., Choi, J.H., Yeom, D.B., Park, J.M. and Hong, S.H. 2006. Application of a temporary palatal prosthesis in a puppy suffering from cleft palate. Journal of Veterinary Science. 7: 93 - 95.

Moura, E., Cirio, S.M. and Pimpao, C.T. 2012. Nonsyndromic cleft lip and palate in boxer dogs: Evidence of monogenic autosomal recessive inheritance. Cleft Palate Craniofacial Journal. 49: 759 760.
Mulvihill, J.J., Mulvihill, C.G. and Priester, W.A. 1980. Cleft palate in domestic animals. Teratology. 21 (1): 109 - 112.

Pearson, L.K. 2016. Congenial and inherited anomalies of mouth. In Merck's Veterinary Manual, (Ed.) Susan Aiello, Merck Sharp and $11^{\text {th }}$ edition, Dohme corp, Kenilworth NJ, USA.

Tobias, K.M. 2010. Oronasal fistulas. In Manual of small animal soft tissue surgery. Wiley-Blackwell publications, Iowa, USA. pp: $361-370$.

Wilson, N. 2006. Surgical repair of traumatic oronasal fistula in a domestic shorthaired cat. Canadian Veterinary Journal. 47: 1210-1213

\section{How to cite this article:}

Mahesh, V., G. Kamalakar, C. Ansar Kamran and Nagaraja, B.N. 2019. Surgical Management of Secondary Cleft Palate in a Cat. Int.J.Curr.Microbiol.App.Sci. 8(08): 2050-2053. doi: https://doi.org/10.20546/ijcmas.2019.808.239 